\title{
Feline primary hyperaldosteronism: an emerging endocrine disease
}

\author{
Hiperaldosteronismo primário felino: uma enfermidade endócrina emergente
}

\author{
Daniel Diola Bento ${ }^{I}$ Fabíola Soares Zahn' ${ }^{\text {II }}$ Laura Carolina Duarte \\ Luiz Henrique de Araújo Machado ${ }^{I V}$
}

\section{- REVIEW -}

ABSTRACT

The primary hyperaldosteronism, an endocrine disease increasingly identified in cats, is characterized by adrenal gland dysfunction that interferes with the renin-angiotensinaldosterone system, triggering the hypersecretion of aldosterone. Pathophysiological consequences of excessive aldosterone secretion are related to increased sodium and water retention, and increased excretion of potassium, which induce hypertension and severe hypokalemia, respectively. The most common clinical findings in cats include: polydipsia, nocturia, polyuria, generalized weakness, neck ventroflexion, syncope, anorexia, weight loss, pendulous abdomen and blindness. Diagnosis is based on the evidence of hormonal hypersecretion with suppression of renin release, imaging and histopathological evaluation of adrenal glands. Treatment may be curative with adrenalectomy, in cases of unilateral disease, or conservative, through administration of aldosterone antagonists, potassium supplementation and antihypertensives. Prognosis varies from fair to good with the appropriate therapy. This article reviews the main aspects of primary aldosteronism in cats, providing the clinician with important information for the diagnosis of this disease.

Key words: feline medicine, endocrinology, adrenocortical disease, hypertension.

\section{RESUMO}

O hiperaldosteronismo primário, doença endrócrina cada vez mais identificada em felinos, caracteriza-se pela disfunção da glândula adrenal com interferência no sistema reninaangiotensina-aldosterona, desencadeando a hipersecreção de aldosterona. As consequências da secreção excessiva de aldosterona estão relacionadas com o aumento da retenção de sódio e água e aumento da excreção de potássio, que ocasionarão, respectivamente, hipertensão arterial sistêmica e hipocalemia grave. $O$ diagnóstico é realizado com base na comprovação da hipersecreção hormonal com supressão da liberação de renina, além de exames de imagem e avaliação histopatológica da adrenal. O tratamento pode ser curativo, com a adrenalectomia, em enfermidades unilaterais, ou conservativo, por meio de antagonistas da aldosterona, suplementação de potássio e anti-hipertensivos. O prognóstico é bom e reservado com a terapia apropriada.

Palavras-chave: medicina felina, endocrinologia, enfermidade adrenocortical, hipertensão.

\section{INTRODUCTION}

First described in humans in 1955, primary hyperaldosteronism, also called Conn syndrome, is an adrenocortical disorder characterized by autonomous adrenal hypersecretion of aldosterone. Initially considered to be rare, hyperaldosteronism is found in approximately $6 \%$ of all hypertensive human patients and accounts for $11 \%$ of those with hypertension non- responding to therapy (FOGARI et al., 2007). The first case in cats was reported in 1983 and currently, though little known and diagnosed, it is considered an important adrenocortical disease in the species (BISGNANO \& BRUYETTE, 2012).

\footnotetext{
IHospital Veterinário Santa Inês, São Paulo, SP, Brasil.

"Departamento de Reprodução Animal e Radiologia Veterinária, Faculdade de Medicina Veterinária e Zootecnia (FMVZ), Universidade Estadual Paulista (UNESP), Botucatu, SP, Brasil

IIIEspecialidades Veterinárias VESP, Campinas, SP, Brasil

IV Departamento de Clínica Veterinária, Faculdade de Medicina Veterinária e Zootecnia (FMVZ), Universidade Estadual Paulista (UNESP), 18618-970, Botucatu, SP, Brasil. E-mail: henrique@fmvz.unesp.br. Corresponding author. Received 09.06.14 Approved 09.22.15 Returned by the author 12.15.15 CR-2014-1327.R7
} 
Aldosterone plays important roles both in the modulation of vascular tone and in the central nervous system function. Mineralocorticoid receptors have been identified in non-epithelial tissues such as heart fibroblasts, endothelial cells, vascular smooth muscle cells and brain. Experiments indicate that increased aldosterone concentrations are associated with increased sympathetic excitatory responses and elevated blood pressure. Aldosterone is considered pro-inflammatory and pro-fibrotic in blood vessels periphery and plays a key role in vascular remodelling and vasoconstriction, thus leading to endothelial dysfunction. Persistent hypertension in primary aldosteronism is therefore a consequence of the synergic effects of sodium and fluid retention, increased sympathetic tone, endothelial dysfunction and increased total peripheral resistance (JEPSON, 2011).

Endocrine physiology of aldosterone

Target organs and tissues

Aldosterone is a steroid hormone with strong mineralocorticoid activity. It was previously thought to be produced only in the adrenal glands; recent studies have shown its production by other tissues including heart, brain and blood vessels, in which it presents both autocrine and paracrine action (CONNELL et al., 2008).

The circulating aldosterone, whose classical targets are kidney epithelium, colon and salivary glands, overpasses the plasma membrane of such tissues and binds to the cytoplasmic mineralocorticoid receptor. Although this receptor presents equal affinity for cortisol and aldosterone, the mineralocorticoid receptors in these tissues enzymatically convert cortisol to cortisone, which has little affinity to the receptor, ensuring the availability of mineralocorticoid receptors for the circulating aldosterone (DJAJADININGRATLAANEN et al., 2011).

Additionally, aldosterone affects other epithelial and non-epithelial tissues that contribute to the homeostasis of blood pressure, including cardiac tissue. Aldosterone increases blood pressure both by the expanding the extracellular fluid, and by increasing peripheral vascular resistance (CONNELL et al., 2008). As demonstrated in humans, long-term excessive mineralocorticoids can trigger microangiopathy, fibrosis and proliferation of endothelium and smooth muscle in tissues such as the heart and kidneys.

Regulation of aldosterone secretion

Aldosterone works by increasing the excretion of potassium and hydrogen and resorption of sodium and chloride in the distal convoluted tubules. Through this mechanism, it regulates systemic blood pressure and homeostasis of extracellular fluid in response to hemodynamic and electrolyte changes (SCHULMAN, 2010).

Its secretion is primarily regulated by the renin-angiotensin-aldosterone system and the extracellular concentrations of potassium. In addition to these mechanisms, there is evidence that aldosterone secretion is also influenced by the adrenocorticotropic hormone $(\mathrm{ACTH})$, natriuretic peptides and certain neurotransmitters. In spite of the significant difference in plasma concentrations of aldosterone observed before and after administration of synthetic ACTH (DECLUE et al., 2011), none of these compounds was proven to directly or indirectly regulate the secretion of aldosterone (DJAJADININGRAT-LAANEN et al., 2011).

Potassium has a direct effect on the zona glomerulosa of the adrenal glands for the secretion of aldosterone. Hyperkalemia stimulates aldosterone secretion by depolarization of the zona glomerulosa cells and hypokalemia inhibits such depolarization. Sodium $(\mathrm{Na}+)$ and potassium $(\mathrm{K}+)$ ions are extremely important and are directly involved in establishing the resting membrane potential. Low serum potassium concentrations prevent the cell from exercising its action potential thus leading to muscle weakness. The nerve cell remains in idle state and can not perform the ion exchange necessary for impulse conduction and muscle tone.

Through the signaling of kidney baroreceptors located in the afferent arterioles, juxtaglomerular apparatus cells increase or reduce the renin secretion in response to decreased or increased circulating blood volume or renal blood flow, respectively. The baroreceptors have the function of regulating blood pressure; when blood pressure is decreased, kidney baroreceptors are activated and sympathetic activity is increased, resulting in increased heart rate and peripheral vasoconstriction.

Sympathetic stimulation acts directly on the macula densa, a group of modified cells in the distal tubules near the end of the loop of Henle and closely associated with juxtaglomerular cells. The concentration of sodium in the tubular lumen is monitored by the macula densa cells, and its reduction can trigger communication between the macula densa and juxtaglomerular cells, resulting in renin release. This released renin is responsible for cleavage of angiotensinogen, produced by hepatic metabolism, in angiotensin I, an inactive peptide which is hydrolyzed in the kidneys to angiotensin II by angiotensin converting enzyme (ACE) (SCHULMAN, 2010). 
Besides its vasoconstrictor effect, angiotensin II stimulates aldosterone secretion. Moreover, circulating concentrations of renin, angiotensin II, and aldosterone are all increased when blood flow to the kidneys is reduced, thus leading to increased sodium retention, increased extracellular fluid and low concentration of extracellular potassium because of urine losses. Once homeostasis has been restored, renin production is reduced and, consequently, so does the concentration of aldosterone (SCHULMAN, 2010).

\section{Metabolism of aldosterone}

Little is known about the metabolism of aldosterone in cats. The liver is often regarded as the most important site of steroid hormones conjugation and inactivation. In cats, cortisol, estradiol and progesterone are mainly excreted via bile (GRAHAM \& BROWN, 1996). Due to the structural similarity, it is expected that the same would occur with aldosterone. According to SYME et al. (2007), urinary excretion of the free form of aldosterone in cats is about 77 times lower than in humans and seven times lower when compared to dogs.

Etiology and pathophysiology of hyperaldosteronism

Two pathophysiological mechanisms can lead to hypersecretion of aldosterone. The reduction in effective arterial blood volume caused by heart failure, kidney disease or severe hypoproteinemia, activates the renin-angiotensinaldosterone system. This physiological response is called secondary hyperaldosteronism or hyperreninemic hyperaldosteronism (DJAJADININGRAT-LAANEN et al., 2011).

In the primary or hyporeninemic hyperaldosteronism, autonomous hypersecretion of aldosterone is held by neoplastic tissue, adrenocortical adenomas or adenocarcinomas, or by nodular hyperplasia of the zona glomerulosa of the adrenal cortex, also known as primary hyperaldosteronism or non neoplastic hyperaldosteronism. In contrast, the secretion of aldosterone in these situations is associated with suppressed renin activity (SCHULMAN, 2010).

Pathophysiological consequences of excessive aldosterone secreted are related to the increase in sodium and water retention, and increased potassium excretion, which can trigger systemic arterial hypertension and severe hypokalemia, respectively. Furthermore, as soon as potassium is shifted to the extracellular compartment, hydrogen ions are moved intracellularly, thus leading to metabolic alkalosis (DJAJADININGRAT-LAANEN et al., 2011).
In humans, six different primary hyperaldosteronism subtypes have been identified, including familial hyperaldosteronism. In contrast to what is observed in humans, in which the primary bilateral idiopathic hyperaldosteronism $(60-65 \%$ of cases), and aldosterone secretory adenoma (30-35\% of cases) represent the majority of cases (YOUNG, 2003; YOUNG, 2007), in cats, hyperaldosteronism is mostly attributed to adenomas or adenocarcinomas of adrenal glands (DJAJADININGRAT-LAANEN et al., 2011). Of 25 cases in cats with histopathological confirmation described in the literature, 13 were related to carcinoma, seven to unilateral adenomas, two to bilateral adenomas and three to bilateral hyperplasia (DJAJADININGRAT-LAANEN et al., 2011).

DeCLUE et al. (2005) reported one case of adenocarcinoma in a cat, with the adrenal glands secreting significant amounts of both aldosterone and progesterone. Young (2003) reported adrenocortical cancer as part of a recognized syndrome in humans, known as multiple endocrine neoplasia (MEN), in which, in the presence of autosomal dominance, the patient develops tumors in endocrine organs, especially pancreas, thyroid, and pituitary. In another case reported the cat presented adrenal adenoma, insulinoma and parathyroid adenoma (REIMER et al., 2005). Despite the data in the literature, DJAJADININGRAT-LAANEN et al. (2011) suggested that the occurrence of adrenocortical hyperplasia may be greater than that reported in cats and suggested that histopathological examination should be essential to determine the cause of the primary hyperaldosteronism in cats, even though it is rarely performed.

Although not identified until the present time, it is believed that some stimulating factor, probably a pituitary peptide present in the circulation, is responsible for adrenocortical hyperplasia (JAVADI et al., 2005). The idiopathic form of the disease can lead to incomplete suppression of renin, while in the neoplastic form there is a complete suppression (ASH et al, 2005; JAVADI et al., 2005; DJAJADININGRATLAANEN et al., 2011). In cats presenting incomplete suppression of renin, the primary hyperaldosteronism becomes an important mediator of the progression of kidney failure. This occurs because of the two circulating mediators of fibroproliferative destruction and vascular changes, aldosterone and angiotensin II (JAVADI et al., 2005).

According to JAVADI et al. (2005), chronic kidney failure has been related to tubulointerstitial and glomerular injury as well as the excessive accumulation of extracellular matrix 
in the kidney. The extracellular matrix accumulation may be mediated by a number of factors, including angiotensin II. Its action is believed to stimulate both renal interstitial fibrosis and mesangial, glomerular endothelial and tubular epithelial hyperplasia and hypertrophy. Regarding aldosterone, JAVADI et al. (2005) reported its contribution to renal injury by promoting vascular fibrosis and thrombosis. In addition, many cats may present evidence of cardiovascular damage secondary to hypertension because of increased intravascular volume, such as murmur, cardiomegaly evidenced by radiographic evaluation and ventricular hypertrophy evidenced by echocardiography (DECLUE et al., 2005).

In humans, the cardiovascular effects of aldosterone hypersecretion are well understood (GIACCHETTI et al., 2009); in cats, however, the role of the primary hyperaldosteronism in the development or progression of heart diseases has not been determined (SCHULMAN, 2010). Care should be taken in cases where the hypersecretion of aldosterone to the cardiovascular system is observed, as in many patients, especially geriatric ones, hypertension, hypokalemia, and azotemia or evidence of cardiovascular changes are misattributed to chronic kidney failure or heart failure as primary disorders rather than the direct effect of primary aldosteronism (DJAJADININGRAT-LAANEN et al., 2011).

\section{Clinical presentation}

Cats diagnosed with primary aldosteronism are mostly geriatrics, although the disturb had already been identified in cats younger than five years (SCHULMAN, 2010). From 40 confirmed or suspected cases of primary hyperaldosteronism reported, the average age was 13 years (DJAJADININGRAT-LAANEN et al., 2011). Apparently there is no predilection for gender or breed (SCHULMAN, 2010).

Primary hyperaldosteronism was reported in 24 domestic shorthair cats, in three domestic longhair cats, two British Shorthairs, and one individual of each of the following breeds: Siamese, Persian, Tonkinese, Burmese, Burmilla (DJAJADININGRAT-LAANEN et al., 2011). Weakness, of sudden or insidious onset, is the most common clinical manifestation, followed by cervical ventroflexion related to hypokalemic polymyopathy, that occurs most commonly with potassium concentrations close to $2.5 \mathrm{mmol} / \mathrm{L}^{-1}$ (EGER et al., 1983; MACKAY et al., 1999; ASH et al., 2005; REIMER et al, 2005).
Potassium is the major intracellular electrolyte and the relationship between its intracellular and extracellular levels is the main determinant of the electric potential of the membranes; any significant change in extracellular potassium concentration can therefore have effects not only on metabolic functions, but also in nerve conduction, with muscular repercussions; hypokalemic polymyopathy is a reflection of this. Hind limbs weakness, episodic spasticity of forelimbs, plantigrade positioning, impaired jumping, flaccid paresis associated to hyporeflexia, dysphagia, respiratory distress, lethargy, and mental depression have been described (ASH et al., 2005; DJAJADININGRAT-LAANEN et al., 2011). From 33 feline cases reported by SCHULMAN (2010), blindness due to retinal detachment or intraocular bleeding as a consequence of systemic hypertension was observed in 11 animals.

Other deleterious effects of hypertension include myocardial hypertrophy and kidney damage (DECLUE et al., 2005). Polyuria, polydipsia, polyphagia or anorexia, urinary incontinence or nocturia, weight loss, and diarrhea are other reported clinical manifestations (SCHULMAN, 2010). Physical examination may reveal a palpable mass in the hypogastric region, pronounced muscular atrophy, the skin fragility syndrome, systolic murmur and irregular heartbeat (BISIGNANO \& BRUYETTE, 2012).

According to a review of 40 cats diagnosed with the disorder (DJAJADININGRAT-LAANEN et al., 2011), hypertension was observed in 31 of 37 cats submitted to blood pressure assessment; ocular changes, including hyphema, mydriasis, increased tortuosity of the retinal vessels, edema and retinal detachment, were observed in 10 of 19 animals submitted to ophthalmologic evaluation; hypokalemic polymyopathy was observed in 19 of 40 cases; signs of congestive heart failure was present in one cat, and no abnormalities were reported in two patients by the first physical assessment.

Regarding laboratory findings in cats, moderate to severe hypokalemia is typically found, although in the early course of the disease the concentrations are within the reference range (DECLUE et al., 2005; JAVADI et al., 2005). Sodium levels are generally normal or slightly increased and indicate a proportional water absorption in relation to the tubular absorption of sodium, triggered by aldosterone (SCHULMAN, 2010). If hypokalemic polymyopathy is observed, the levels of creatine kinase (CK) are markedly increased (AHN, 1994). This is explained as severe hypokalemia can lead to 
an acute muscular injury, which triggers the release of extremely toxic components into the circulation, most notably myoglobin and CK (GOTO et al., 2009).

Because of the potential to precipitate or worsen an existing chronic renal injury, the cats may also present isosthenuria and increased serum creatinine and the concentrations of nitrogen compounds (EGER et al., 1983; ASH, 2005). Furthermore, proteinuria is a common finding due to both the direct action of aldosterone hypersecretion and hypertension (JAVADI et al., 2005). Although no study has effectively demonstrated its prevalence, metabolic alkalosis can be observed in patients with primary hyperaldosteronism since extracellular potassium translocation leads to hydrogen ions moving into the intracellular compartment (DJAJADININGRAT-LAANEN et al., 2011).

Primary hyperaldosteronism in humans may be associated with metabolic syndrome, characterized by insulin resistance, inadequate function of beta cells, circulating pro-inflammatory proteins and prothrombotic tendency (FALLO et al., 2006; SCHULMAN, 2010). Although there is no parameter established in feline medicine, DJAJADININGRAT-LAANEN et al. (2011), reported in their review that all four cats with specified glucose determination were hyperglycemic.

\section{Diagnosis}

Aldosterone: plasma renin ratio

In cats, the gold standard to differentiate the primary hyperaldosteronism from the secondary hyperaldosteronism is the aldosterone: renin ratio, being 0.3 to 3.8 the established reference value (JAVADI et al., 2004; JAVADI et al., 2005). Thus, cats with adrenocortical tumors have very high plasma aldosterone activity and, in general, completely suppressed plasma renin activity, since the secretion is independent of the stimulation of the renin-angiotensin-aldosterone system (JAVADI et al., 2005). In the case of bilateral hyperplasia, however, the obtained plasma renin activity may be slightly increased or within the upper reference limits (DJAJADININGRAT-LAANEN et al., 2011).

Care must be taken in obtaining the samples to ensure the accuracy of the test, p.e. the obtainment of appropriate amount $(>4 \mathrm{~mL})$ and immediate freezing after centrifugation. The reference ranges for plasma renin activity vary widely between laboratories, which complicates the interpretation and standardization of the test (DJAJADININGRATLAANEN et al., 2011). Moreover, few laboratories offer the plasma renin test, which often requires the clinician to use the assessment of aldosterone activity as a single test (DECLUE et al., 2005). JAVADI et al. (2004) determined a reference value of $80-450 \mathrm{pmol}$ $\mathrm{L}^{-1}$ (28.8 to162.2pg ml-1) for plasma aldosterone activity from studies in healthy cats, and reported that neither stress nor body condition affected the concentrations. Nevertheless, the same authors recommend that plasma aldosterone activity should always be based on serum potassium concentrations, as hypokalemia is decisive for reduced aldosterone secretion. Thus, an aldosterone activity at or above the laboratory reference values is inappropriate in hypertensive or hypokalemic cats (JAVADI et al., 2004; LO et al., 2014.).

Urinary aldosterone: creatinine ratio

The assessment of the urinary aldosterone to creatinine ratio was recently investigated in cats. Although the amount of excreted aldosterone through urine in cats is smaller than in humans or dogs (SYME et al., 2007), the ratio can be determined and the sample is both easy to obtain and representative of the aldosterone circulation during the whole period of the collected urine production (SCHULMAN, 2010). This has been shown to be a practical and noninvasive method in the diagnosis of primary hyperaldosteronism in cats when combined with the suppression induced by salt or fludrocortisone acetate (DJAJADININGRAT-LAANEN et al., 2013). This drug was shown to cause a significant reduction on urinary aldosterone to creatinine ratio in healthy cats, but not in an animal with confirmed primary hyperaldosteronism.

\section{Other tests}

The adrenocorticotropic hormone (ACTH) stimulates the production of aldosterone and may be used to evaluate adrenal mineralocorticoid production (BISIGNANO \& BRUYETTE, 2012). Exogenous ACTH causes reliable increase in aldosterone secretion and a recommended IV dose of $125 \mu \mathrm{g}$ ACTH per cat has been used, followed by blood sample collection 60 to 75 minutes after the hormone administration (DECLUE et al., 2011). Despite this possibility of ACTH use, BISIGNANO \& BRUYETTE (2012) concluded that such a test is of questionable utility.

An ideal test based on the suppression of aldosterone production in normal cats, but presenting little or no effect on those patients with primary hyperaldosteronism, would be the best method to confirm that hyperactivity of zona glomerulosa is the responsible for the increased activity of plasma 
aldosterone (BISIGNANO \& BRUYETTE, 2012). In a study by DJAJADININGRAT-LAANEN et al. (2013) the fludrocortisone suppression test was effective to exclude the diagnosis of primary hyperaldosteronism in cats presenting plasma aldosterone: renin ratio within the reference range. This test should be performed in cats with plasma aldosterone: renin ratio between $7.5 \times 10^{-9}$ and $46.5 \times 10^{-9}$; fludrocortisone should be given at $0.05 \mathrm{mg}$ $\mathrm{kg}^{-1} 12 \mathrm{~h}^{-1}$ for 4 days.

The ratio is determined in the morning urine before, during and after the fourth day of administration; a suppression lower than $50 \%$ indicates inadequate secretion of aldosterone. The fludrocortisone suppression test cannot predict the etiology of the disease and before performing the test, blood pressure of the animal should be evaluated; hypertension was not observed in this study. Potassium levels should be assessed before and during the test, as fludrocortisone can lead to hypokalemia. Some tests are already available in human medicine, p.e. the captopril stimulation test, the saline infusion test and the oral administration of sodium test (DJAJADININGRATLAANEN et al., 2011).

\section{Imaging}

Imaging tests, aiming on checking the laterality of the disease (essential in guiding the choice of therapy), should be performed in all patients in which primary hyperaldosteronism is suspected, specially when screening tests indicate abnormal regulation of aldosterone secretion. The clinical and laboratory suspicion must coexist, as changes in the image not necessarily corresponding to hyperaldosteronism but to the other kind of hormone producing or non producing lesion may occur. In these cases, surgery may be unnecessary or even lead to death, for example in the case of a pheochromocytoma that is operated without adequate pharmacological preparation (BISIGNANO \& BRUYETTE, 2012).

In cats, the abnormalities observed during ultrassonographic examination in patients with primary hyperaldosteronism may vary from the presence of calcification and masses to changes in echogenicity of the adrenal glands (MACKAY et al., 1999; ASH et al., 2005). Both computed tomography and magnetic resonance imaging can be used to improve the image obtained from the adrenal glands in cats (ASH et al., 2005). In a study performed by JAVADI et al. (2005), from 11 cats diagnosed with hyperaldosteronism, only two exhibited normal appearance of the adrenal glands on ultrasound or CT scan and all the others presented minor visible abnormalities.

Abnormalities in adrenal glands may still correspond to cortisol or progesterone secreting masses, pheochromocytomas or nonfunctional masses and the finding of abnormal adrenal glands do not necessarily imply hypersecretion of aldosterone. For this reason, imaging evaluation is only performed after confirming hyperaldosteronism in humans (DECLUE et al., 2005).

\section{Treatment and prognosis}

For cats with unilateral primary aldosteronism with no evidence of metastasis, adrenalectomy is the therapy of choice and is curative for both adenoma and adenocarcinoma with signs of hypokalemia or hypertension, with resolution of the clinical manifestations eliminating additional postoperative therapy (ASH et al., 2005; ROSE et al, 2007; LO et al., 2014). In human patients, in which aldosterone is secreted by adenomas, the control of blood pressure after adrenalectomy is achieved in $50-60 \%$ of cases (DUESBERG \& PETERSON, 1997).

Post operative complications may occur and include sepsis, bleeding and thromboembolism (DECLUE et al., 2005). These complications were reported in 8 of 18 surgical cases in cats, 6 of them being fatal (MACKAY et al., 1999; RIJNBERK et al., 2001; ASH et al., 2005; DECLUE et al., 2005).

Drug therapy with administration of spironolactone, potassium supplementation and antihypertensive agents is required in many cats, especially those presenting idiopathic hyperaldosteronism. The reported survival time in cats with conservative therapy ranges from several months up to years (ASH et al., 2005). Spironolactone, an aldosterone receptor antagonist in the distal convoluted tubules and renal collecting ducts, promotes potassium retention and sodium excretion. The initial dose of $2 \mathrm{mg} \mathrm{kg}^{-1}$ every 12 hours may be increased up to a maximum of $4 \mathrm{mg}$ $\mathrm{kg}^{-1}$, above which it may cause anorexia, diarrhea and emesis. Potassium supplementation, preferably oral, is required in refractory cases. The medication of choice for persistent hypertension is amlodipine, a calcium channel blocker, at an initial dose of $0.1 \mathrm{mg}$ $\mathrm{kg}^{-1}$ every 24 hours (BISIGNANO \& BRUYETTE, 2012; DJAJADININGRAT-LAANEN et al., 2011).

Mainly because of non-selective affinity of spironolactone for androgen, estrogen and progesterone receptors in humans, a new generation of aldosterone antagonists, eplerenone, 
began to be used in human patients with primary hyperaldosteronism (KARAGIANNIS et al., 2008). This medication has not been tested in veterinary medicine. The prognosis for cats with bilateral adrenal hyperplasia, despite the relative effectiveness of drug therapy, is not as good when compared to patients with adrenocortical cancer who underwent surgical treatment, which have better prognosis.

\section{CONCLUSION}

Primary hyperaldosteronism is probably the most common adrenocortical disease in cats. In any feline patient, especially geriatric and hypertensive patients, the disease should be investigated. If hyperaldosteronism is suspected, plasma aldosterone concentrations should be evaluated and confronted with serum potassium levels. The patient should be then submitted to the ultrasonographic examination; even though it is not a precise exam, it may be useful to determine the adrenocortical laterality.

Due to the common association between hypokalemia/hypertension and chronic kidney disease, hyperaldosteronism is often not considered as a differential diagnosis, pushing such patients away from appropriate therapy. Moreover, blood pressure is poorly monitored in clinical practice, which contributes to the under-diagnosis of the disease. With the spreading of this technique, however, a considerable increase in the number of reported cases is expected in the next years, when a greater knowledge regarding the disease in cats should be available, especially concerning diagnosis.

\section{REFERENCES}

AHN, A. Hyperaldosteronism in cats. Seminars in Veterinary Medicine and Surgery, v.09, n.03, p.153-157, Aug. 1994.

ASH, R.A. et al. Primary hyperaldosteronism in the cat: a series of 13 cases. Journal of Feline Medicine and Surgery, v.07, n.03, p.173-182, Jun. 2005. Available from: $<$ http://www.sciencedirect. com/science/article/pii/S1098612X04001408>. Accessed: Nov. 06, 2014. doi: 10.1016/j.jfms.2004.08.007.

BISIGNANO, J.; BRUYETTE, D.S. Feline hyperaldosteronism: recognition and diagnosis. Veterinary Medicine, 1 Mar. 2012. Online. Available from: <http://veterinarymedicine.dvm 360 . com/feline-hyperaldosteronism-recognition-and-diagnosis $>$. Accessed: Nov. 06, 2014.

CONNELL, J.M.C. et al. A life time of aldosterone excess: longterm consequences of altered regulation of aldosterone production for cardiovascular function. Endocrine Reviews, v.29, n.02, p.133-154, Apr. 2008. Available from: <http://press.endocrine. org/doi/abs/10.1210/er.2007-0030>. Accessed: Oct. 10, 2014. doi: $10.1210 /$ er.2007-0030
DeCLUE, A.E. et al. Cortisol and aldosterone response to various doses of cosyntropin in healthy cats. Journal of American Veterinary Medical Association, v.238, n.02, p.176-182, Jan. 2011. Available from: <http://avmajournals.avma.org/doi/ abs/10.2460/javma.238.2.176>. Accessed: Oct. 12, 2014 . doi: 10.2460/javma.238.2.176

DeCLUE, A.E. et al. Hyperaldosteronism and hyperprogesteronism in a cat with an adrenal cortical carcinoma. Journal of Veterinary Internal Medicine, v.19, n.03, p.355358, May. 2005. Available from: <http://onlinelibrary.wiley.com/ doi/10.1111/j.1939-1676.2005.tb02708.x/abstract>. Accessed: Oct. 10, 2014. doi: 10.1111/j.1939-1676.2005.tb02708.x.

DJAJADININGRAT-LAANEN, S.C. et al. Primary hyperaldosteronism: expanding the diagnostic net. Journal of Feline Medicine and Surgery, v.13, n 09, p.641-650, Sept. 2011. Available from: $<$ http://jfm.sagepub.com/content/13/9/641.short>. Accessed: Oct. 14, 2014. doi: 10.1016/j.jfms.2011.07.017.

DJAJADININGRAT-LAANEN, S.C et al. Evaluation of the oral fludrocortisone suppression test for diagnosing primary hyperaldosteronism in cats. Journal of Veterinary Internal Medicine, v.27, n.06, p.1493-1499, Nov/Dec. 2013. Available from: <http://onlinelibrary.wiley.com/doi/10.1111/jvim.12216/ full>. Accessed: Jan. 05, 2015. doi: 10.1111/jvim.12216.

DUESBERG, C.; PETERSON, M.E. Adrenal disorders in cats Veterinary Clinics of North America. Small Animal Practice, v.27, p.321-347, Mar. 1997.

EGER, C.E. et al. Primary aldosteronism (Conn's syndrome) in a cat; a case report and review of comparative aspects. Journal of Small Animal Practice, v.24, n.05, p.293-307, May. 1983.

FALLO, F. et al. Prevalence and characteristics of the metabolic syndrome in primary aldosteronism. J Clin Endocrinol Metab, v.91, n.2, p.454-459, Nov. 2005. Available from: <http://www. ncbi.nlm.nih.gov/pubmed/16291704>. Accessed: Aug. 11, 2015. doi: $10.1210 /$ jc. $2005-1733$.

FOGARI, R. et al. Prevalence of primary aldosteronism among unselected hypertensive patients: a prospective study based on the use of an aldosterone/renine ratio above 25 as a screening test. Hypertension Research, v.30, n.02, p.111117, Dec. 2007. Available from: <http://www.nature.com/ hr/journal/v30/n2/abs/hr200717a.html>. Accessed: Nov. 06, 2014. doi: 10.1291/hypres.30.111.

GIACCHETTI, G. et al. Management of primary aldosteronism: its complications and their outcomes after treatment. Current Vascular Pharmacology, v.07, n.02, p.244-249, Apr. 2009. Available from: <http://www.ingentaconnect.com/content/ben/ cvp/2009/00000007/00000002/art00014>. Accessed: Oct. 10, 2014. doi: $10.2174 / 157016109787455716$.

GOTO, A. et al. Primary aldosteronism associated with severe rhabdomyolysis due to profound hypokalemia. Internal Medicine, v.48, n.04, p.219-223, 2009. Available from: <http:// europepmc.org/abstract/MED/19218772>. Accessed: Nov. 08 , 2014. doi:10.2169/internalmedicine.48.1444.

GRAHAM, L.H.; BROWN, J.L. Cortisol metabolism in the domestic cat and implications for non-invasive monitoring of adreno-cortical function in endangered felids. Zoo Biology, v.15, n.01, p.71-82, Mar. 1996 
JAVADI, S. et al. Plasma renin activity and plasma concentrations of aldosterone, cortisol, adrenocorticotropic hormone and alpha melanocyte-stimulating hormone in healthy cats. Journal of Veterinary Internal Medicine, v.18, n.05, p.625-631, Sept. 2004. Available from: <http://onlinelibrary. wiley.com/doi/10.1111/j.1939-1676.2004.tb02597.x/abstract $>$. Accessed: Oct. 14, 2014. doi: 10.1111/j.1939-1676.2004. tb02597.x.

JAVADI, S. et al. Primary hyperaldosteronism, a mediator of progressive renal disease in cats. Domestic Animal Endocrinology, v.28, n.01, p.85-104, Jan. 2005. Available from: <http://www.sciencedirect.com/science/article/pii/ S0739724004000931>. Accessed: Oct. 14, 2014. doi: 10.1016/j.domaniend.2004.06.010.

JEPSON, R. Feline systemic hypertension: classification and pathogenesis. Journal of feline medicine and surgery, v.13, n.01, p.25-34, Jan. 2011. Available from: <http://jfm.sagepub. com/content/13/1/25.short $>$. Accessed: Jan. 06, 2011. doi: 10.1016/j.jfms.2010.11.007.

KARAGIANNIS, A. et al. Medical treatment as an alternative to adrenalectomy in patients with aldosterone-producing adenomas. Endocrine-Related Cancer, v.15, n.03, p.693-700, Sept. 2008. Available from: $<$ http://erc.endocrinology-journals. org/content/15/3/693.short>. Accessed: Oct. 18, 2014. doi: 10.1677/ERC-08-0094.

LO, A.J. et al. Treatment of aldosterone-secreting adrenocortical tumors in cats by unilateral adrenalectomy: 10 cases (20022012). Journal of Veterinary Internal Medicine, v.28, n.01, p.137-147, Jan/Feb. 2014. Available from: <http://onlinelibrary. wiley.com/doi/10.1111/jvim.12186/full>. Accessed: Nov. 04, 2014. doi: $10.1111 /$ jvim. 12186 .

MACKAY, A.D. et al. Successful surgical treatment of a cat with primary hyperaldosteronism. Journal of Feline Medicine and Surgery, v.01, n.02, p.117-122, Jun. 1999.
REIMER, S.B. et al. Multiple endocrine neoplasia type I in a cat. Journal of the American Veterinary Medical Association, v.227, n.01, p.101-104, Jul. 2005. Available from: <http://avmajournals. avma.org/doi/abs/10.2460/javma.2005.227.101?journalCode=jav ma>. Accessed: Oct. 14, 2014. doi: 10.2460/javma.2005.227.101.

RIJNBERK, A. et al. Hyperaldosteronism in a cat with metastasised adrenocortical tumour. Veterinary Quarterly, v.23, n.01, p.38-43, Jan. 2001.

ROSE, S.A. et al. Adrenalectomy and caval thrombectomy in a cat with primary hyperaldosteronism. Journal of the American Animal Hospital Association, v.43, n.04, p.209-214, Jul./ Aug. 2007. Available from: <http://europepmc.org/abstract/ MED/17615401>. Accessed: Oct. 16, 2014.

SCHULMAN, R.L. Feline primary hyperaldosteronism. Veterinary Clinics of North America: Small Animal Practice, v.40, n.02, p.353-359, Mar. 2010. Available from: $<$ http://www. sciencedirect.com/science/article/pii/S0195561609001776>. Accessed: Oct. 15, 2014. doi: 10.1016/j.cvsm.2009.10.006.

SYME, H.M. et al. Measurement of aldosterone in feline, canine and human urine. Journal of Small Animal Practice, v.48, n.04, p.202-208, Apr. 2007. Available from: <http://onlinelibrary.wiley. com/doi/10.1111/j.1748-5827.2006.00264.x/full>. Accessed from: Oct. 10, 2014. doi: 10.1111/j.1748-5827.2006.00264.x.

YOUNG, W.F . Minireview: primary aldosteronism-changing concepts in diagnosis and treatment. Endocrinology, v.144, n.06, p.2208-2213, Jun. 2003. Available from: <http://press.endocrine. org/doi/abs/10.1210/en.2003-0279>. Accessed: Oct. 16, 2014. doi: 10.1210/en.2003-0279.

YOUNG, W.F. Primary aldosteronism: renaissance of syndrome. Clinical Endocrinology, v.66, n.05, p.607-618, May. 2007. Available from: <http://onlinelibrary.wiley.com/doi/10.1111/ j.1365-2265.2007.02775.x/full>. Accessed from: Oct. 16, 2014. doi: $10.1111 /$ j.1365-2265.2007.02775.x. 